\section{Acupuncture for} 'frequent attenders' with medically unexplained symptoms

The June issue of the BJGP has a paper, "Acupuncture for "frequent attenders" with medically unexplained symptoms: a randomised controlled trial ICACTUS study)'. I' has lots of numbers, but the result is very easy to see. Just look at Figure 2 lomitted from the print version, online only). ${ }^{1}$

There is no need to wade through all the statistics; it's perfectly obvious at a glance that acupuncture has, at best, a tiny and erratic effect on any of the outcomes that were measured. The effects, even if some are real, are obviously too small to be of any clinical significance. The paper is fascinating because it is the clearest demonstration I have ever seen that acupuncture is ineffective, and that it does not even have a worthwhile placebo effect. One may certainly criticise the lack of a sham acupuncture control group but, in a sense, that is what makes the paper fascinating. Despite the inability of the experimental design to distinguish between non-specific effects and genuine effects of acupuncture, next to no benefit was seen. The result may have been fascinating, but its significance was lost altogether on the authors. The conclusion of the paper said:

'The addition of 12 sessions of fiveelement acupuncture to usual care resulted in improved health status and wellbeing that was sustained for 12 months."

The meaning of the paper was also lost on the Editor, who issued a press release:

Although there are countless reports of the benefits of acupuncture for a range of medical problems, there have been very few well-conducted, randomised controlled trials. Charlotte Paterson's work considerably strengthens the evidence base for using acupuncture to help patients who are troubled by symptoms that we find difficult both to diagnose and to treat.

Both of these statements directly contradict what is actually apparent from the figure.

One wonders what went wrong. Presumably the referees, like the authors, were partisan when it comes to needling. We don't know because the Editor has declined to release the reports. It is harder to explain the press release. All one can conclude is that the paper had not been read very carefully before the press release was written. Mistakes of this sort do great harm to journals. The paper in question has already been analysed carefully in four blogs (two of them by GPs $)^{2-5}$ and has been the subject of a devastating spoof in The Daily Mash. ${ }^{6} \mathrm{Had}$ the Editor admitted the mistaken interpretation, one could have forgotten the matter. We all make mistakes sometime. By refusing to admit that the paper and the press release were very misleading, the Journal has been brought into disrepute.

\section{David Colquhoun,}

Professor of Pharmacology, University College London, Gower Street, London, WC1E 6BT. E-mail: d.colquhounaucl.ac.uk

\section{REFERENCES}

1. Paterson C, Taylor RS, Griffiths $P$, et al. Acupuncture for 'frequent attenders' with medically unexplained symptoms: a randomised controlled trial (CACTUS study). Br J Gen Pract 2011; DOI: 10.3399/bjgp11X572689.

2. Colquhoun D. Acupuncturists show that acupuncture doesn't work, but conclude the opposite: journal fails. DC's Improbable Science, 2011. http://www.dcscience.net/?p=4439 laccessed 11 Jul 2011).

3. McCartney M. The British Journal of General Practice does acupuncture badly. Margaret McCartney's blog: a forum on healthcare policy, 2011.

http://www.margaretmccartney.com/blog/?p=981 laccessed 11 Jul 2011).

4. Lawson E. BJGP and acupuncture - tabloid medical journalism. Northern Doctor's Antidote, 2011. http://northerndoctor.com/2011/06/02/bjgpand-acupuncture-tabloid-medical-journalism/ laccessed 11 Jul 2011).

5. Lewis A. Of the imagination, as a cause and as a cure of disorders of the body. The Quakometer, 2011.

http://www.quackometer.net/blog/2011/06/of-theimagination-as-a-cause-and-as-a-cure56of- disorders-of-the-body.html laccessed 11 Jul 2011).

6. The Daily Mash. Made-up medicine works on made-up illnesses. The Daily Mash, 2011. http://www.thedailymash.co.uk/index.php?option=c om_content\&task=view\&id=3882\& Itemid=77 (accessed 11 Jul 2011).

DOI: 10.3399/bjgp11X588268

The headline in June's BJGP says that five-element acupuncture "has a significant and sustained benefit' [print version only]. ${ }^{1}$ The associated editorial says that the review offers 'more evidence for the effectiveness of acupuncture'. 2 The heading on the front cover says

'Acupuncture: effective ...'

I feel that these are misleading. Many GPs, and the media, rely on the headlines and editorials to be accurate, as we don't have time to read every article. What this rather small study actually shows is that the whole acupuncture consultation made a significant difference in just one of the three wellbeing scores used, but did not make a significant difference in two of the three scores, nor in consultation rates. ${ }^{1}$ The authors acknowledge that their study does not show that needling itself was responsible for any changes seen, and also explain that they didn't choose a sham-acupuncture control because it may interfere with the participative patient-therapist interaction'.

I am not going to debate here all the other evidence regarding acupuncture, but I feel strongly that the BJGP needs to be more responsible in how it headlines articles and in printing editorials that make claims regarding efficacy that is not supported by the evidence.

\section{Louise Cockram,}

Sessional GP, 94 Queens Road, Gosport, Hampshire, P012 1LH.

E-mail: louisecockramadoctors.org.uk

\section{REFERENCES}

1. Paterson C, Taylor RS, Griffiths P, et al. Acupuncture for 'frequent attenders' with medically unexplained symptoms: a randomised controlled trial (CACTUS study). Br J Gen Pract 2011; DOI: 10.3399/bjgp11X572689.

2. Shan WSY, Ho CVC. Acupuncture: filling the effectiveness gaps in Western medicine? Br J Gen Pract 2011; 61(587): 374-375.

DOI: 10.3399/bjgp11X588277 